\title{
Eighty years of Redfield
}

\author{
The outstanding lifespan of the canonical Redfield ratio has shown the power of elemental stoichiometry \\ in describing ocean life. But the biological mechanisms governing this consistency remain unknown.
}

In 1934, Alfred C. Redfield reported a suite of dissolved nitrate, phosphate and oxygen measurements from various depths in the Atlantic, Pacific and Indian oceans. These data showed a remarkable consistency, with nitrate and phosphate occurring in a ratio of about 20:1 in most of these samples ${ }^{1}$. Later refined to 16:1, and expanded to include a ratio of carbon to phosphate of 106:1, this Redfield ratio has come to define our understanding of ocean biogeochemical cycling. Along with this issue, we present a web focus (http://www.nature.com/ngeo/ focus/redfield/index.html) showing that just as the identification of this near-constant ratio laid the foundations for the twentiethcentury advances in our understanding of marine biogeochemistry, deviations from this ratio are now providing twenty-firstcentury insights into the nutrient dynamics of oceans modern and ancient.

The fact that across all the ocean basins and depths studied, nutrient concentrations occurred in a constant ratio was surprising in the 1930s. The key link, Redfield surmised, was related to the corresponding oxygen levels. Specifically, oxygen concentrations measured in the samples were lower than $t$ would be expected from atmospheric equilibration - and also formed a constant ratio with nitrate and phosphate concentrations. Perhaps not incidentally writing in a volume honouring a prominent marine biologist, Redfield suggested that the covariance is what might be expected "if the different samples contained the products of the complete disintegration and oxidation of organic matter of a similar composition" Any differences in absolute concentrations must reflect a varying supply of this organic matter.

The Redfield ratio has been revisited time and again in the ensuing years. In fact, Google Scholar returns 17 articles with the phrase "Redfield revisited" in the title; citations to these papers number in the hundreds. These articles confirm the overall consistency of the ratio, but also reveal some surprising deviations. Indeed, the steadiness of the average proportions of nutrients may mask differences in the C:N:P content of different species. And still other organisms may be able to vary their nutrient content.

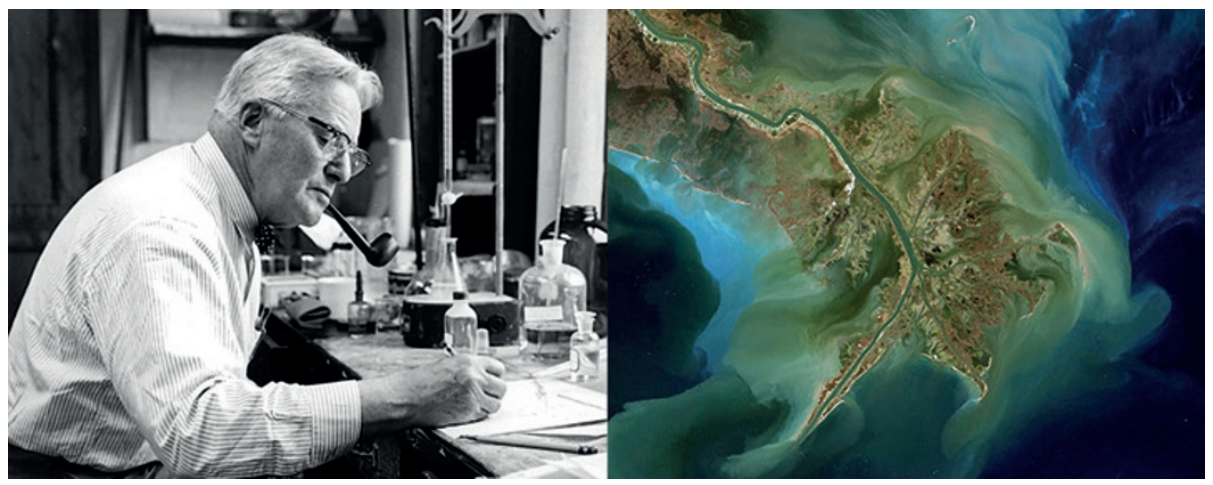

The work done by Alfred Redfield (left) paved the way for our understanding of how the runoff of nitrogen and phosphorus from fertilized lands fuels phytoplankton blooms like those near the mouth of the Mississippi River (right). Left photo courtesy of the Woods Hole Oceanographic Institution Archives; right photo (c) NASA/Landsat/Phil Degginger/Alamy.

For instance, algae and cyanobacteria in culture seem to have a surprising flexibility in their $\mathrm{N}: \mathrm{P}$ ratios, ranging from 5:1 to 100:1, depending on which nutrient was in short supply ${ }^{3}$.

This flexibility suggests that the utility of the Redfield ratio may have been limited during the first three billion years of marine life, when cyanobacteria were the dominant phytoplankton group, as argued in a commentary on page 855 of this issue. However, this flexibility does explain how this relatively simple life form was able to flourish even in the face of (probable) phosphate limitation during the first two or so billion years of Earth's history.

Deviations also occur systematically across latitudes and circulation systems, possibly as a result of changes in the phytoplankton ecology. These variations have a pronounced effect on the C:P ratios of both living biomass and of sinking organic matter, as reported on pages 890 , 895 and 862 . High C:P ratios of sinking biomass in low nutrient areas suggest that phytoplankton can be economical with their phosphorus requirements when the supply is deeply limited.

Redfield was prescient in his explanations of nutrient supply and shortages, which he expanded on in $1958^{4}$. As a commentary on page 853 discussed, Redfield proposed that the key to the ratio's stability was in the cycling of nitrogen into and out of bioavailable forms, as other nutrients became available or limiting. This hypothesis was borne out by the discovery of marine diazotrophs, a group of bacteria and archaea that are able to convert $\mathrm{N}_{2}$ into a bioavailable form of nitrogen, as well as other microbes that are capable of converting bioavailable nitrogen back to $\mathrm{N}_{2}$.

Redfield was, however, not able to explain why his ratio persisted across so many marine biomes. The fact that cyanobacteria vary so greatly in their $\mathrm{N}: \mathrm{P}$ ratio is one argument against a purely physiological control ${ }^{2}$. The Redfield ratio could arise from the partitioning of nutrient resources during growth and protein synthesis ${ }^{5,6}$. Maybe physiology only governs the N:P ratio of some organisms, with the resulting nutrient pools taking less dominant organisms like cyanobacteria along for the ride.

As the Redfield ratio enters its ninth decade there is still much to be discovered. We now need to move beyond showing that it persists to explaining why it exists.

\section{References}

1. Redfield, A. C. in James Johnstone Memorial Volume (ed. R. J. Daniel) 177-192 (Univ. Press of Liverpool, 1934).

2. Klausmeier, C. A., Litchman, E., Daufresne, T. \& Levin, S. A. Nature 429, 171-174 (2004).

3. Geider, R. \& La Roche, J. Eur. J. Phycol. 37, 1-17 (2002).

4. Redfield, A. C. Am. Sci. 46, 205-221 (1958).

5. Arrigo, K. Nature 437, 349-355 (2004).

6. Bonachela, J. A., Allison, S. D., Martiny, A. C. \& Levin, S. A. Biogeosciences 10, 4341-4356 (2013). 